\title{
Entrevista na Escola Secundária Fernão de Magalhães
}

Da esquerda para a direita: Dra. Amélia Chaves, Dr. Fernando Castro, Dra Otilia Barreira e Dra. Lília Zita.

Os alunos da Escola Secundária Fernão de Magalhães, em Chaves, surpreenderam ao arrebatar o $1 .^{\circ}, 3 .^{\circ} \mathrm{e} 4 .^{\circ}$ lugares das "Olimpíadas de Química - 2001", entre 27 finalistas oriundos de todo o pais, e colocando assim 3 alunos nos 4 representantes de Portugal nas Olimpíadas Ibero-americanas. Quisemos conhecer melhor a sua Escola e os seus professores, e entrevistámos o Dr. Fernando Castro, presidente do Conselho Executivo da Escola, a Dra. Amélia Chaves, delegada do $4 .{ }^{\circ}$ Grupo B, a Dra. Otília Barreira, que os acompanhou nas "Olimpíadas", e a Dra. Lília Zita, sua professora de Química.

Dr. Fernando Castro, começo por lhe perguntar se é de Chaves...

FC - Eu não sou de Chaves, sou de uma aldeia - Ferreirim - do Concelho de Ser-

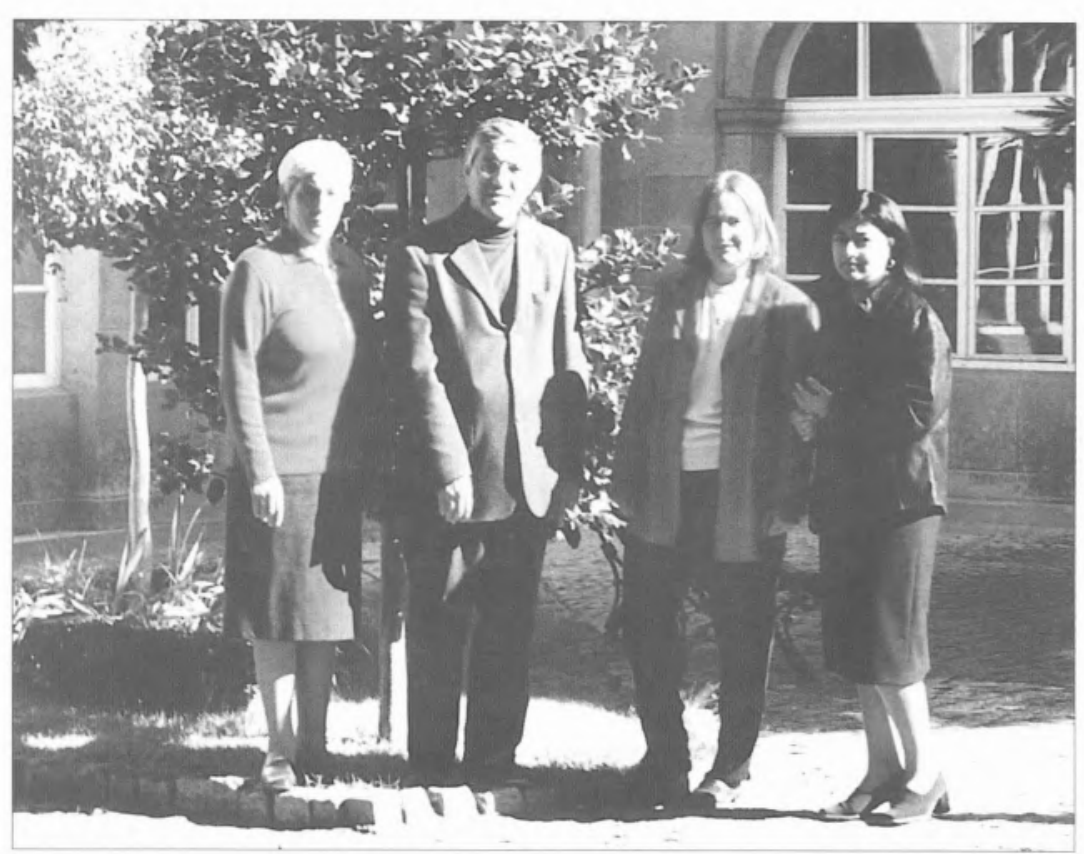

nancelhe, e vim para Chaves dar aulas, depois conheci aqui a minha mulher e fiquei cá.

Vou pedir-lhe para localizar a Escola no seu meio. Sei que não é a única Escola Secundária de Chaves. Que população serve e quantos alunos a frequentam?

FC - Neste momento temos à volta de 1100 alunos, 726 diurnos e o resto nocturnos. Na cidade há três Escolas secundárias (mais $30^{\circ}$ Ciclo). Fiz um levantamento recente sobre a origem dos alunos e temos à volta de metade do meio rural e metade do meio urbano. A Escola tem cursos de carácter geral dos agrupamentos 1 e 4. Tem também um curso tecnológico de "Animação Social" dentro do agrupamento 4 , embora com muito poucos alunos.
Como presidente do Conselho Executivo, o que mais aprecia na Escola?

FC - O que mais aprecio na Escola... (pausa)... o edifício é bonito, é um edificio antigo, foi um antigo convento, tem claustros, tem uns azulejos logo à entrada bastante bonitos...e o ambiente na Escola em si é um ambiente bom. Aqui o interior às vezes tem essa vantagem, com os seus alunos mais humildes do meio rural, o que também torna o ambiente agradável... e temos cá bons professores e não temos casos de indisciplina.

E agora o outro lado: quais as maiores dificuldades com que lida?

FC - Os laboratórios de Física e Química e Biologia, são laboratórios antigos, como os dos antigos liceus, têm ainda as mesas em ardósia, torneiras antigas, o que torna as aulas mais dificeis. $E$ 


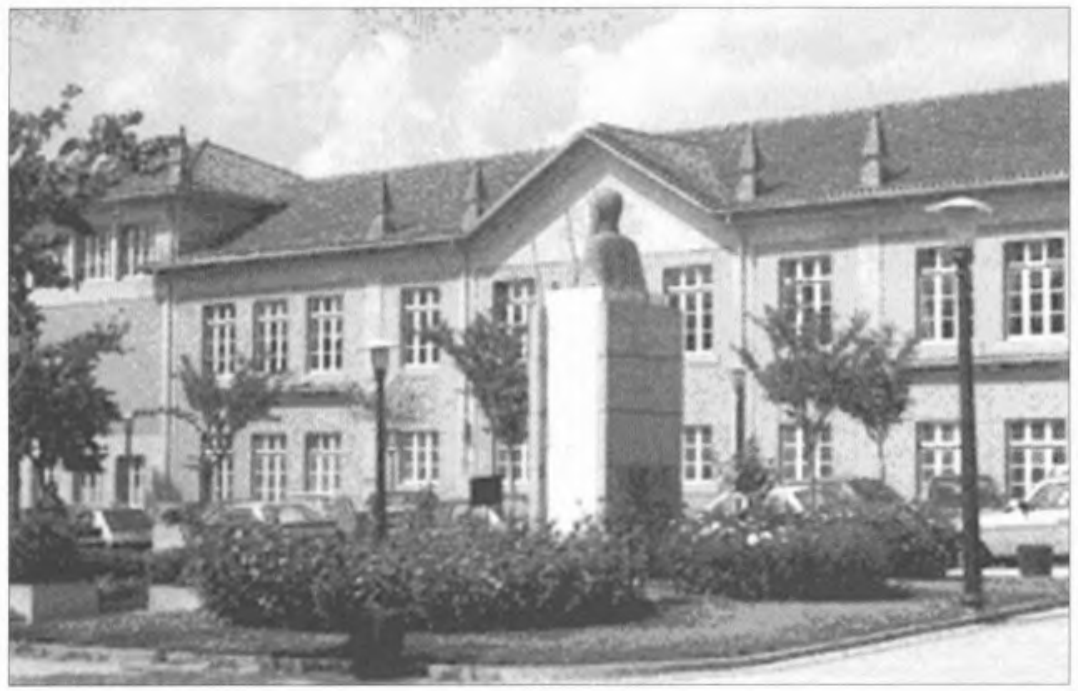

temos também poucos espaços, temos dificuldade em arranjar gabinetes para contacto com os pais, salas de estudo, etc. A biblioteca é também um espaço pequeno, que vamos ampliar, mas para isso precisamos de a juntar a uma sala anexa, e isso é difícil. Também temos falta de algum equipamento para os laboratórios. A nivel de informática, vêm agora aí alguns computadores que farão muito jeito à sala de informática e não só...

No ano passado, a Escola distinguiu-se pela prestação dos seus alunos nas "Olimpíadas de Química". É habitual que os alunos da Escola participem neste tipo de actividades?

FC - Os alunos da Escola têm participado nas "Olimpiadas" de Química, Matemática, Física... a Escola apoia nas viagens e em tudo o que for necessário. São os próprios professores que gostam de se envolver nestes assuntos e mobilizam os alunos.

Uma pergunta que se tornou obrigatória tem a ver com a classificação da Escola no tão falado "ranking" dos exames nacionais. Nas disciplinas das ciências exactas a Escola aparece entre - $22 .^{\circ}$ (Física) e o $46 .^{\circ}$ (Matemática) lugares. Parece-me um resultado confortável...

$\mathrm{FC}$ - $\mathrm{O}$ que eu tenho dito a outras pessoas é que desde que há exames nacionais, a Escola tem tido sempre boas médias. Em Química, já houve anos an- teriores em que houve até melhores médias... mas nós temos andado pelas médias de 12 . Em relação à divulgação do "ranking", é discutivel, mas eu acho que tem alguma vantagem, pelo menos a de reparar situações que vinham sendo prejudiciais para alguns alunos. Há Escolas que dão boas médias a nível interno, mas que os exames baixam. Outras dão classificações internas mais baixas, mas que os alunos sobem nos exames, e esses alunos são prejudicados.

Em contacto com os professores desta Escola, verifiquei que se referiam frequentemente à Escola como "Escola do interior". Aliás, isso sucedeu há pouco na nossa conversa. É algo assim tão marcante? Reflecte-se na "vida" da Escola, no seu funcionamento?

FC - Aqui na Escola, se calhar não se notará muito, mas em relação a outras Escolas acho que sim, porque a população docente é uma população muito volante, param por cá um ano, têm afazeres no litoral... e isso acaba por prejudicar a Escola do interior. Mas, por acaso, nós aqui até temos um corpo docente bastante estável, o que contribui para a qualidade da Escola.

Isso era a pergunta que lhe ia fazer a seguir. O corpo docente desta Escola é de maioria estável ou flutuante?

FC - A maioria é estável. Nós temos aqui à volta de 117 professores e 80 são fixos, e já com muita experiência, o que contribui para que haja um núcleo de professores exigente e rigoroso.
Escola Secundária Fernão de Magalhães

$E$ acha que isso contribui para que a Escola funcione mais como corpo, que haja colaborações entre professores fora das suas áreas...?

FC - O corpo docente estável contribui, de facto, para que haja mais interdisciplinaridade. Aqui na Escola não há aquela que se desejaria, mais vai havendo alguma...

E agora falando com as Professoras... Dra. Amélia Chaves, Dra. Otilia Barreira, Dra. Lília Zita, a mesma pergunta inicial: porquê Chaves?

AC - Sou natural de uma aldeia a $12 \mathrm{~km}$ de Chaves (S. António de Monforte). Fiz o liceu no Colégio Interno em Vila Real, tirei o curso de Engenharia Química no Técnico, em Lisboa, e formei-me no ano do 25 de Abril, numa altura em que houve uma crise de emprego na indústria. Então vim para Chaves e comecei a trabalhar como professora, mas com ideia de arranjar um trabalho de engenharia...mas gostei do ensino, também porque sou de uma família de professores, e fui ficando no ensino, sou solteira, e dediquei-me aos alunos.

LZ - Eu nẫo sou de Chaves, sou do Porto (Vila Nova de Gaia) e vim para aqui porque os meus pais tinham cá amigos, já há uns anos que vinha para Chaves de férias, e na hora de me efectivar concorri para aqui. E depois fui ficando... 
$O B$ - Eu estudei nesta Escola. O meu ensino secundário foi feito na Fernão de Magalhães.

Dra. Otília, uma antiga colega (e admiradora) sua disse-me que a sua opção pelo ensino secundário foi uma grande perda para a universidade, embora um grande ganho para o ensino secundário...

OB - (risos) Eu comecei por trabalhar no Ensino Superior na universidade em Lourenço Marques. Em 1977 regressei e, por razões familiares tive de me fixar aqui, e iniciei a minha carreira no secundário...? Em Moçambique tinha já começado algum trabalho de investigação e quando regressei estava a pensar continuar, até porque tinha hipóteses de vir a trabalhar para a minha universidade, que era no Porto. Simplesmente, tinha dois filhos pequenos e naquela altura eram tempos dificeis, tivemos que optar por ficar aqui.

\section{Lamenta não ter ficado na Universida- de?}

$\mathrm{OB}$ - Não, quer dizer... é outro tipo de ensino, mas eu estou satisfeita. Eu gosto do trabalho que faço no secundário. É um tipo de relação professor/aluno muito diferente. Nós aqui conseguimos ter um tipo de relação que não se consegue no superior, pelo menos na altura em que eu lá trabalhei.

Vou repetir outra pergunta que já fiz ao Dr. Fernando Castro. Como professoras, o que mais apreciam na Escola?

LZ - São os alunos! Essa é fácil! (risos).

Pelo menos eu tenho tido sorte e tenho tido bons alunos. Aqueles que não são bons estudantes são excelentes pessoas, o que tem permitido um contacto muito agradável com eles. $E$ há uma coisa que eu também gosto muito, que é o não ter trânsito na ida para a Escola...

$\mathrm{OB}$ - Eu tenho uma relação de afectividade com a Escola muito grande. Foi a minha Escola, foi onde eu fiz todo o ensino secundário. Depois, como docente do secundário foi praticamente a única Escola onde trabalhei, após o estágio no Porto.
$\mathrm{AC}$ - $\mathrm{O}$ que gosto mais na Escola é o ambiente, em particular dentro do grupo, porque nós colaboramos todos, trabalhamos em conjunto. Se há um que vai a uma reunião, o que aprende lá traz aos outros... colaboramos todos e somos todos amigos. Claro que fora do grupo também há pequenos atritos, mas são coisas que se resolvem com facilidade.

Também gosto da Escola porque os nossos alunos correspondem àquilo que nós pretendemos deles, são trabalhadores e são educados.

\section{E o que gostam menos...?}

LZ - Essa é mais difícil. Há determinadas burocracias para organização de actividades que se tornam aqui muito complicadas. Eu posso comparar, porque estive uns anos em Guimarāes, que é um meio industrial, e para fazer pequenas exposições ou organizar encontros, havia sempre apoios, falava-se com as indústrias e elas estavam sempre dispostas a ajudar e a participar. Aqui não há indústria, praticamente, e a sensibilidade é um bocadinho diferente.

OB - Em termos da nossa disciplina, temos os laboratórios minimamente equipados e conseguimos que a parte experimental tenha a sua importância na aprendizagem dos miúdos. Em termos gerais, não é uma Escola que tenha uma grande biblioteca, uma sala de convivio... por aí os alunos estão bastante prejudicados, embora por outro lado, como a Escola está no centro da cidade, têm muito apoio da biblioteca municipal. Muitos dos nossos alunos recorrem à biblioteca Municipal, que está razoavelmente equipada.

AC - As limitaçōes maiores que temos são as instalações. A Escola era um antigo convento de freiras. Só temos dois laboratórios, daqueles antigos de liceu, não temos sala de apoio, não temos sala de reagentes, não temos instalação de gás, funcionamos com botijas... as instalações são muito, muito reduzidas.

Mas nós trabalhamos! Mesmo por vezes os professores mais novos que chegam põem dúvidas, mas nós, "os velhos" como nós dizemos, fazemos tudo: no
$12 .^{\circ}$ ano fazemos os trabalhos laboratoriais todos, nas técnicas de Química também. Com o que temos, vamos trabalhando e conseguimos...

Isso tem também a ver com o facto de muitos professores da Escola serem "fixos"...

AC - No quadro somos 6 ou 7 professores fixos e que já estamos na Escola há mais ou menos 18 anos. Somos um corpo fixo e trabalhamos com os alunos e gostamos de trabalhar com os alunos... e é isso que nos leva a ter bons resultados.

E portanto, o corpo docente da Escola funciona como um corpo.... há trabalho interdisciplinar...

OB - Na parte da disciplina, Físico-Química, o grupo funciona muito bem. $\mathrm{Na}$ parte interdisciplinar, funciona principalmente com os professores de Ciências da Terra e da Vida e de Matemática.

AC - Há agora um projecto aqui na Escola com duas colegas, uma delas é a Lilia, ela poderá falar sobre isso. Eu vou às reuniões e colaboro com elas. No ano passado colaborei com a Geologia sobre a sintese dos cristais: não trabalhamos muito, mas estamos a começar a trabaIhar mais. Com as técnicas de Biologia é que trabalho: se eles precisam de mim eu auxilio-os na minha aula, se eu preciso delas, elas auxiliam-me nas aulas delas...

LZ - Eu gostaria que houvesse muito mais. Dentro do grupo é mais fácil, porque temos reunióes periódicas e vamos fazendo algumas coisas, embora isso dependa sempre da disponibilidade das pessoas e da vontade que têm, não é algo institucionalizado.

Com os outros grupos, é muito mais complicado, porque não há um espaço de reunião. Há uma ideia que vem com este novo modelo de gestão, que é a questão dos departamentos, que tinha como intenção juntar alguns grupos disciplinares para eles poderem trabalhar em conjunto. Na nossa Escola não funcionou porque os grupos disciplinares constituiram departamentos e, portanto, continuámos exactamente como estáva- 


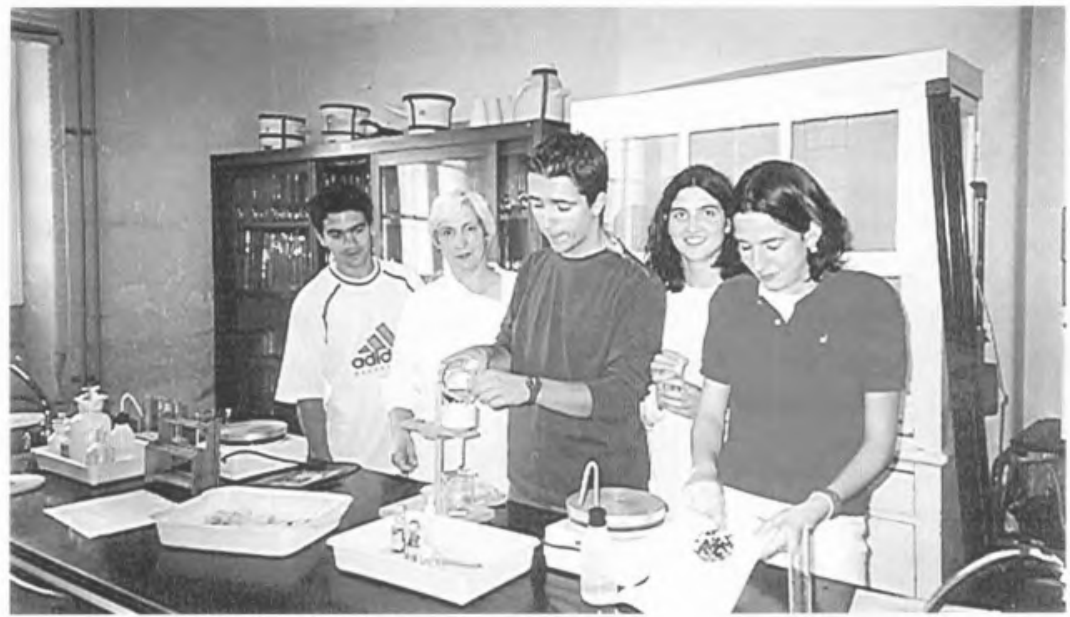

mos antes. Daí que não haja muito trabalho conjunto...

As suas colegas parecem mais optimistas: era desejável que houvesse mais trabalho conjunto, mas vai havendo algum...

$\mathrm{LZ}$ - Sim, vai havendo algum. 0 trabalho que estou a fazer no acompanhamento do ensino das ciências é com colegas do grupo de Biologia e Geologia. Nesse sentido temos desenvolvido alguns projectos, com alunos em comum, etc., e temos tentado motivar as outras pessoas para fazerem o mesmo. E tem havido colaborações, mas não é algo regular, é esporádico, que se prende com o conjugar pessoas que se dão bem e trabalham bem e que têm a mesma turma. Mas não é uma coisa que exista, como deveria existir, por sistema. Sobretudo, e eu estou sensivel a isso tipo de coisas, ao nivel das ciências, porque há matérias comuns à Química, Física, Biologia ou Geologia, e por vezes nem sequer há a preocupação de trabalhar a mesma linguagem. Mas isto não é um defeito (só) da minha Escola!

Mas a Dra. Lília já me foi apontada (por uma formadora sua) como tendo actividade importante no campo da formação de professores...

LZ - Eu estou ligada a um projecto do DES (Departamento do Ensino Secundário), fiz uma acção de formação no sentido de dar apoio à implementação dos novos currículos, que começam no próximo ano. Nós temos a tarefa de fazer reuniões com algumas Escolas da região para tentar modificar o que se pre- tende modificar ao nível dos novos curriculos, sobretudo nas actividades experimentais.

E a questão da "Escola do interior"? Afecta o dia a dia da Escola?

$A C$ - Eu penso que não. Eu não sinto que na vida da Escola o ensino seja mais deficiente do que nas Escolas do litoral e não me sinto limitada por ser de uma Escola do interior. Se nós gostarmos de trabalhar, trabalhamos. Eu também não conheço Escolas do litoral. Deve haver Escolas que estão mais perto das universidades e portanto com mais apoio. Ai sinto falta de apoio... nas reuniões que há - até da SPQ, da qual eu sou sócia desde o início - e eu não posso ir. Para me deslocar a Lisboa ou a Aveiro, são dias..

LZ - Eu também penso que não se sente esse peso no dia a dia da Escola. Agora há questões em termos de orçamento... e depois, o facto de estarmos aqui num "cantinho" torna mais difícil o contacto com determinados meios, como os meios industriais - para fazer visitas, para obter apoios.

No dia a dia da Escola não pesa, pesa mais é na hora de organizar coisas e tentar fazer coisas diferentes... ai sente-se algum peso da interioridade... e nós, para mais, estamos num "cantinho", longe de coisas com as quais seria interessante os nossos alunos estarem em permanente contacto.

$\mathrm{OB}$ - Reflecte-se mais na medida em que as possibilidades, os contactos que nós temos com as novas técnicas são
Laboratório

mais dificeis. Nós somos um grupo de professores que tentamos superar isso. Por exemplo, posso dizer-Ihe que todo o programa FOCO e todas as acções de formação que fiz, fui fazê-las ao Porto, à minha Universidade. De qualquer modo, o problema não é para professores - contactar com a Universidade e tentar fazer uma aprendizagem continua -, é mais para os alunos: os alunos de uma Escola do Porto têm outras possibilidades, acesso a outros recursos, que os nossos não têm. Os professores deslocam-se mais facilmente, e posso dizer-Ihe que na nossa Escola deslocamo-nos para acções de formação e somos nós que as pagamos do nosso bolso...

Isto é um pouco ao lado do tema da nossa conversa, mas há quem sinta que a importância social dos professores do ES se tem vindo a esbater. Sentem que aqui em Chaves (no tal "interior"), o professor ainda é uma referência cultural da comunidade? Ou esse prestígio também já não se nota em Chaves?

LZ- Eu não noto diferenças aqui em relação a outros meios que conheço, e conheço bem o Porto, Gaia, etc., onde tenho muitos colegas e amigos

OB - Se vamos pôr em paralelo, numa Escola de uma cidade do interior a questão social pode ser importante, mais do que numa cidade grande... temos o médico, o juiz... o professor tem o seu papel... Aqui nesta cidade até há um grupo de professores que tem dinamizado algumas actividades e, portanto, 
continuam a ter um certo prestígio. Mas, efectivamente, há cada vez mais um esvaziamento da função do professor na sociedade. Não tem a importância que já teve.

$\mathrm{AC}-\ldots$ e de ano para ano isso vai-se alterando. Antigamente, nós professores tínhamos um determinado nivel e éramos menos. Agora já há muitos professores vindos de muitas Escolas, alguns chegam sem preparação cultural e até científica... o que acaba por dar um mau aspecto exterior à Escola. As pessoas dizem "Olha, e é professor!". Não sei se quando era nova trazia essa preparação, mas acho que vinha melhor preparada. Mesmo não sendo de um curso de ensino, vinha melhor preparada que muitos destes novos colegas.

Vamos voltar às "Olimpíadas de Química" e ao excelente resultado obtido pela Escola no ano passado. É habitual os vossos alunos participarem em iniciativas do género?

LZ - Nas "Olimpiadas de Física", sempre desde que sou professora nesta Escola. Tive uma orientadora de estágio que participava na organização das "Olimpiadas" a nivel do Porto e portanto "meteu-nos o bichinho" destas coisas. As "Olimpiadas de Química" não têm existido com tanta regularidade...

[Mas estamos (SPQ) a trabalhar para que sejam regulares...]

AC - Já organizámos aqui na nossa Escola, há alguns anos, as "Olimpíadas" a nivel regional. Nessa altura até ganharam uns alunos de Lamego, mas os nossos também se portaram bem.

A Escola apoia essas iniciativas, só que não dá dinheiro... temos de ser nós a colaborar. A Escola dá-nos todo o apoio na questão da organização. 0 apoio monetário não tem dado, porque a nossa Escola também tem um orçamento limitado e o dinheiro não chega para tudo.

Como foi seleccionada a equipa? Eram todos da mesma turma?

$\mathrm{OB}$ - Foram contactados os colegas que estavam leccionar as várias turmas do $12 .^{\circ}$ ano e os alunos constituíram-se em equipas e concorreram alunos de diver- sas turmas. Os que ganharam eram todos da mesma turma.

LZ - São da mesma turma, e meus alunos, desde o $8 .^{\circ}$ ano. Já os conheço bastante bem.

Havia uma clara distinção em relação aos restantes, ou é uma Escola tão rica que tinha mais como eles?

$\mathrm{OB}$ - Excepcionalmente, nós este ano tínhamos um grupo de alunos muito bons. E mesmo entre os que foram eliminados, havia alunos talvez tão bons como estes. Aliás, os nossos resultados a nível da Química foram muito bons.

LZ - Eu tenho tido sempre um "grupinho" de bons alunos. Agora esta turma, era uma turma excepcional, porque além daqueles três havia outros três que eram igualmente bons alunos, e outros que estariam perto. Era uma turma muito boa no geral, e sempre foram assim, desde o $8 .^{\circ}$ ano. Aquilo que eu consegui fazer foi manter-Ihes a motivação.

Ficou surpreendida com os resultados dos alunos nas "Olimpíadas"?

LZ - Não (risos). Eu tinha ideia que eram muito bons e podiam ter uma boa participação, mas já levei outros alunos muito bons a "Olimpiadas" e eles não ganharam...

$A C$ - Os alunos não eram meus alunos, mas eu não fiquei surpreendida, fiquei contente. Surpreendida não, porque eu já sabia que este ano havia um grupo muito jeitoso de alunos. Da nossa Escola entraram este ano para Medicina 6 ou 7 alunos, outros para Farmácia, para Bioquimica... e houve classificações de 20 a Química, também uns 6 ou 7...

Ora aí está um tema interessante: os alunos que venceram as "Olimpíadas de Química" já estão na Universidade e nenhum deles num curso parecido com Química...

OB - Estão os três em Medicina...

Pois é...! Sentem que há uma quebra do interesse dos jovens pela Química, que a Química tem uma má imagem, não os atrai?
OB - Não é uma questão da Química não os atrair. A maioria dos nossos alunos até preferem a Química à Física. 0 problema não está em gostar ou não gostar de Química, está em que eles vêm mais o futuro... hoje o único curso que Ihes dá garantia de emprego é Medicina... Também não acho que todos os bons alunos tenham tendência para ser médicos... há também qualquer coisa de influência familiar... não tem a ver com uma má imagem da Química. Um dos alunos das "Olimpiadas" tem um laboratório de Química em casa desde $08^{\circ}$ ano e é excelente a nível experimental... tenho imensa pena que não vá para Química..

LZ - Eu acho que não tem a ver com uma má imagem da Quimica, tem a ver com a falta de informação que eles têm das possibilidades que a Quimica poderá ter a nivel profissional. Há alguma falta de esclarecimento por parte dos alunos. Normalmente, o que os preocupa é a saida profissional, a possibilidade de ganhar dinheiro depois. E tenho a sensação que eles pensam que a Química não tem saidas profissionais. Eles conhecem aquelas profissões mais faladas... medicina... direito... engenharia...

Mas neste caso, lembro-me que eles, quando fizeram as fichinhas do $8 .^{\circ}$ ano, já queriam ir para Medicina.

Agora também digo, actualmente, os alunos que estudam e que se aplicam, são aqueles que querem ir para Medicina, porque sabem que têm uma tarefa complicada pela frente. Os outros, vão levando as coisas alegremente, estudando quanto baste (risos), ou nada, dependendo das perspectivas..

AC - Os nossos alunos também entram para Química, para engenharia Química, para Engenharia Biológica em Braga. E entram muitos para o ensino da Química: há uma Escola nova aqui na cidade cujos professores foram todos nossos alunos. E temos alunos que ficaram na Universidade do Minho, como professores de Química. E temos um aluno a doutorar-se em Bioquímica nos Estados Unidos... 